\title{
Depression and anxiety in a case series of amyotrophic lateral sclerosis: frequency and association with clinical features
}

\author{
Depressão e ansiedade em uma série de casos de esclerose lateral amiotrófica: \\ frequência e associação com aspectos clínicos
}

Laura de Godoy Rousseff Prado ${ }^{1}$, Isabella Carolina Santos Bicalho' ${ }^{1}$, Mauro Vidigal-Lopes 2 , Vitor de Godoy Rousseff Prado ${ }^{1}$, Rodrigo Santiago Gomez ${ }^{1}$, Leonardo Cruz de Souza ${ }^{1}$, Antônio Lúcio Teixeira ${ }^{1}$

\section{ABSTRACT}

Objective: To investigate the frequency of anxiety and depression and their association with clinical features of amyotrophic lateral sclerosis. Methods: This is a cross-sectional and descriptive study including a consecutive series of patients with sporadic amyotrophic lateral sclerosis according to Awaji's criteria. Patients underwent clinical and psychiatric assessment (anxiety and depression symptoms). Results: We included 76 patients. The men/women ratio was 1.6:1. Participants' mean age at disease onset was 55 years $(S D \pm 12.1)$. Sixty-six patients (86.8\%) were able to complete psychiatric evaluation. Clinically significant anxiety was found in 23 patients (34.8\%) while clinically significant depression was found in 24 patients $(36.4 \%)$. When we compared patients with and without depression a significant difference was seen only in the frequency of anxiety symptoms $(p<0.001)$. We did further analysis comparing subgroups of patients classified according to the presence or not of anxiety and or depression, without any significant difference regarding sex, age at onset, initial form, disease duration or functional measures. A positive correlation between anxiety and depressive symptoms was found $(p<0.001)$. Conclusion: Anxiety and depressive symptoms were highly correlated and frequent in patients with amyotrophic lateral sclerosis. In addition, anxiety and depression were not associated with disease duration and presentation, sex, age at onset, and functional score.

Keywords: Amyotrophic lateral sclerosis/diagnosis; Depression; Anxiety

\section{RESUMO}

Objetivo: Investigar a frequência de ansiedade e depressão e sua associação com aspectos clínicos da esclerose lateral amiotrófica. Métodos: Estudo transversal e descritivo de uma série consecutiva de pacientes com esclerose lateral amiotrófica esporádica conforme os critérios de Awaji. Os pacientes foram submetidos à avaliação clínica e psiquiátrica (sintomas depressivos e ansiosos). Resultados: Foram incluídos 76 pacientes. A relação homem/mulher foi de 1,6:1. A média de idade de início dos sintomas foi de 55 anos $(\mathrm{DP} \pm 12,1)$. Foram capazes de completar a avaliação psiquiátrica $66(86,8 \%)$ pacientes. Ansiedade clinicamente significativa foi encontrada em 23 pacientes $(34,8 \%)$, enquanto depressão clinicamente significativa foi encontrada em 24 pacientes $(36,4 \%)$. Ao comparar os pacientes com e sem depressão, houve diferença significativa apenas na frequência de sintomas de ansiedade $(p<0,001)$. Posteriormente, foram comparados subgrupos de pacientes categorizados em relação à presença ou não de ansiedade e/ou depressão, sem diferença significativa em relação a sexo, idade de início dos sintomas, forma inicial, duração da doença ou na escala funcional. Foi encontrada correlação positiva entre os sintomas de ansiedade e depressão $(p<0,001)$. Conclusão: Sintomas de ansiedade e depressão são frequentes em pacientes com esclerose lateral amiotrófica e estiveram altamente correlacionados. Ansiedade e depressão não foram associadas com duração da doença, forma inicial, sexo, idade de início dos sintomas e pontuação na escala funcional.

Descritores: Esclerose amiotrófica lateral/diagnóstico; Depressão; Ansiedade

\footnotetext{
Universidade Federal de Minas Gerais, Belo Horizonte, MG, Brazil.

2 Fundação Hospitalar do Estado de Minas Gerais, Hospital Júlia Kubitschek, Belo Horizonte, MG, Brazil.

Corresponding author: Laura de Godoy Rousseff Prado - Rua Alfredo Balena, 190, sala 281 - Santa Efigênia - Zip code: 30130-100 - Belo Horizonte, MG, Brazil - Phone: (55 31) 3409-8072 E-mail: laura.grp@hotmail.com

Received on: Sep 17, 2016 - Accepted on: Jan 4, 2017

Conflict of interest: none.
}

DOI: 10.1590/\$1679-45082017A03870 


\section{INTRODUCTION}

Amyotrophic lateral sclerosis (ALS) is characterized by motor neuron degeneration leading to progressive muscle paresis and functional disability, with a mean survival of 3 to 5 years. ${ }^{(1)}$ Non-motor symptoms may be seen including depression and anxiety. ${ }^{(1,2)}$ The prevalence of depression and anxiety is highly variable among published studies, and may be present in up to 44 and $30 \%$ of patients, respectively.(2) There is evidence indicating that functional disability and depression are linked, and that depression reduces the quality of life of patients with ALS. ${ }^{(3)}$ However, some studies failed to confirm the association between the severity of anxiety and depressive symptoms, and functional disability in ALS. ${ }^{(4,5)}$

This study investigated clinical features and anxiety/ depressive symptoms in Brazilian patients with ALS. We hypothesized that the presence of anxiety and depression would be related to a more significant functional impairment.

\section{OBJECTIVE}

To investigate the frequency of anxiety and depression and their association with clinical features of amyotrophic lateral sclerosis.

\section{METHODS}

This is a cross-sectional study of consecutive patients diagnosed with probable or definite sporadic ALS according to Awaji's criteria ${ }^{(6)}$ conducted from May 2013 to November 2015. All patients signed the written consent.

The protocol included standardized questions regarding clinical features of ALS, the Hospital Anxiety and Depression Scale (HADS) ${ }^{(7,8)}$ and the ALS Functional Rating Scale Revised (ALSFRS-R). ${ }^{(9)}$ A total score on HADS for depression above 8 is highly indicative of clinically significant depression (i.e. probable depression); the same criteria was applied for anxiety. ${ }^{(8)}$

The study was approved by the human research Ethics Committee of both Universidade Federal de Minas Gerais, CAAE: 19599813.0.0000.5149 and Fundação Hospitalar do Estado de Minas Gerais, protocol number 002B/2014.

\section{Statistical analysis}

We performed non-parametric tests (Mann-Whitney, $\chi^{2}$ and Spearman) using Statistical Package for the Social Sciences (SPSS), version 22.0. A p value $<0.05$ was considered statistically significant.

\section{RESULTS}

Seventy-six patients were selected for the study. The clinical parameters are summarized at table 1 . Fortyseven patients $(61.8 \%)$ were men (men/women ratio: 1.6:1). Considering the initial presentation, $78 \%$ of cases were spinal and $22 \%$ were bulbar.

Table 1. Descriptive analysis of clinical parameters of patients with amyotrophic lateral sclerosis

\begin{tabular}{lcccc}
\hline Sporadic ALS (n=76) & $\begin{array}{c}\text { Mean } \\
\text { (SD } \mathbf{~})\end{array}$ & Median & Minimun Maximun \\
\hline Age at the onset of symptoms, years & $55.0(12.1)$ & 55 & 26 & 82 \\
Age at assessment, years & $58.3(11.6)$ & 58 & 32 & 83 \\
Disease duration until assessment, years & $3.32(2.8)$ & 2 & 0 & 14 \\
\hline
\end{tabular}

ALS: amyotrophic lateral sclerosis; SD: standard deviation.

Sixty-six patients $(86.8 \%)$ completed the HADS (Table 2). The others did not fulfill the scale due to refusal $(n=4)$ or severe disability $(n=6)$. Probable anxiety was confirmed in $23(34.8 \%)$ patients; probable depression was found in $24(36.4 \%)$ patients. Of 66 patients, $65 \%$ were men, $50(75 \%)$ had spinal and 16 $(24 \%)$ had bulbar initial presentation. Fifteen $(23 \%)$ had anxiety and depression, 9 (14\%) had only depression, $8(12 \%)$ had only anxiety, while $34(51 \%)$ had none of these symptoms. Thirty patients were current using antidepressants to treat depressive state and/or pain, insomnia or excessive salivation. Eleven of 24 patients with depression $(45.8 \%)$ were using effective doses of antidepressants.

When we compared subgroups of patients according to the presence or not of probable depression, there was a statistical difference regarding the score on HADS for anxiety (Table 3). No significant difference was found regarding sex and initial form.

We did further analysis comparing subgroups of patients categorized according to the presence or not of anxiety and or depression, and no significant difference regarding ALSFRS-R scores, sex, age at onset, disease duration and initial form emerged.

Table 2. Descriptive analysis of clinical parameters of patients with amyotrophic lateral sclerosis who completed Hospital Anxiety and Depression Scale

\begin{tabular}{lcccc}
\hline Sporadic ALS $(\mathbf{n}=\mathbf{6 6})$ & Mean $(\mathbf{S D} \mathbf{\pm})$ & Median & Minimun & Maximun \\
\hline Age at the onset, years & $54.3(12.1)$ & 55 & 26 & 82 \\
Age at assessment, years & $57.6(11.5)$ & 57,5 & 32 & 83 \\
Score on ALSFRS-R & $26.9(10.1)$ & 27 & 0 & 46 \\
Score on HADS-anxiety & $7.2(4.4)$ & 6 & 0 & 17 \\
Score on HADS-depression & $6.7(4.5)$ & 7 & 0 & 18 \\
\hline
\end{tabular}

ALS: amyotrophic lateral sclerosis; ALSFRS-R: amyotrophic lateral sclerosis functional rating scale revised; HADS: hoSpital anxiety and depression scale; SD: standard deviation. 
Table 3. Comparative analysis of subgroups of patients, according to presence or the absence of significant depressive symptoms (Hospital Anxiety and Depression Scale for depression $\geq 9$ )

\begin{tabular}{|c|c|c|c|c|c|}
\hline & \multicolumn{4}{|c|}{ Depression } & \multirow{3}{*}{ p value } \\
\hline & \multicolumn{2}{|r|}{ Yes } & \multicolumn{2}{|r|}{ No } & \\
\hline & $\mathbf{n}$ & mean $(\mathbf{r})$ & $\mathbf{n}$ & mean $(\mathbf{r})$ & \\
\hline Years of study & 24 & $6.4(3-19)$ & 42 & $7.3(0-20)$ & 0.66 \\
\hline Age at the onset of disease, years & 24 & $58.1(41-76)$ & 42 & $52.1(26-82)$ & 0.06 \\
\hline Anxiety & 24 & $10.8(4-17)$ & 42 & $5.2(0-15)$ & $0.00^{*}$ \\
\hline Score on ALSFRS-R & 24 & $25.8(0-46)$ & 42 & $27.6(4-46)$ & 0.44 \\
\hline Disease duration, years & 24 & $3.0(0-11)$ & 42 & $3.4(0-14)$ & 0.60 \\
\hline
\end{tabular}

There was no correlation between HADS scores for anxiety or depression and ALSFRS-R scores. A positive correlation between anxiety and depressive symptoms was found $(r=0.67 ; p<0.001)$.

\section{DISCUSSION}

To the best of our knowledge, this is the first study assessing psychiatric symptoms in ALS patients from South America. The frequency of depression (zero to $44 \%$ ) and anxiety (zero to $30 \%$ ) in ALS varies significantly across the studies. ${ }^{(2,3,4)}$ Our rates (around $35 \%$ ) are within the range reported in the literature.

The assessment of psychiatric symptoms in ALS may be hampered by several factors, including assessment tools ${ }^{(10)}$ and severity of the disease, ${ }^{(3,11)}$ partly explaining the discrepancy among studies. Moreover, the use of antidepressants, that is frequent in ALS for different reasons, ${ }^{(2-4,12)}$ may have influenced the frequency and/or severity of depressive and anxiety symptoms.

Interestingly, despite the use of antidepressants, psychiatric symptoms are prominent, indicating persistence of symptoms even with treatment. ${ }^{(2,3,12)}$ It remains to be defined whether these patients respond differently to antidepressants and which factors are associated to clinical response.

Contrary to our hypothesis, we did not find significant association between symptoms of anxiety/ depression and functional disability. The absence of association between depression and disease duration or functional score in ALS were reported in some studies, ${ }^{(4,5)}$ but other authors did find this association. ${ }^{(3)}$ Methodological issues, including differences in the selection criteria of patients and in the choice of the functional and psychiatric scales may account for these distinct findings. The controversial findings in literature hamper a precise conclusion about this subject. Further studies could help to clarify this data.

Based on the absence of significant difference in clinical features between subgroups, it is possible that these psychiatric symptoms may be due to other reasons not related to motor and functional impairment. It also remains to be elucidated why anxiety and depression symptoms were highly correlated in ALS. Limitations of the study include sample size, bias of the use of antidepressants and intrinsic limitations of the HADS.

\section{CONCLUSION}

The frequency of anxiety and depression in amyotrophic lateral sclerosis was elevated, and was not associated with disease duration, sex, presentation form and functional score. There was a high correlation between anxiety and depression symptoms in amyotrophic lateral sclerosis.

\section{REFERENCES}

1. Kiernan MC, Vucic S, Cheah BC, Turner MR, Eisen A, Hardiman O, et al Amyotrophic lateral sclerosis. Lancet. 2011;377(9769):942-55. Review.

2. Kurt A, Nijboer F, Matuz T, Kübler A. Depression and anxiety in individuals with amyotrophic lateral sclerosis: epidemiology and management. CNS Drugs. 2007;21(4):279-91. Review.

3. Rabkin JG, Goetz R, Factor-Litvak P, Hupf J, McElhiney M, Singleton J, Mitsumoto H; Als Cosmos Study Group. Depression and wish to die in a multicenter cohort of ALS patients. Amyotroph Lateral Scler Frontotemporal Degener. 2015;16(3-4):265-73.

4. Atassi N, Cook A, Pineda CM, Yerramilli-Rao P, Pulley D, Cudkowicz M Depression in amyotrophic lateral sclerosis. Amyotroph Lateral Scler. 2011; 12(2):109-12.

5. Chen D, Guo X, Zheng Z, Wei O, Song W, Cao B, et al. Depression and anxiety in amyotrophic lateral sclerosis: correlations between the distress of patients and caregivers. Muscle Nerve. 2015;51(3):353-7.

6. de Carvalho M, Dengler R, Eisen A, England JD, Kaji R, Kimura J, et al Eletrodiagnostic criteria for diagnosis of ALS. Clin Neurophysiol. 2008;119(3): 497-503. Review.

7. Zigmond AS, Snaith RP. The hospital anxiety and depression scale. Acta Psychiatr Scand. 1983;67(6):361-70.

8. Botega NJ, Bio MR, Zomignani MA, Garcia Jr C, Pereira WA. [Mood disorders among medical in-patients: a validation study of the hospital anxiety and depression scale (HAD)]. Rev Saude Publica. 1995;29(5):355-63. Portuguese.

9. Guedes K, Pereira C, Pavan K, Valerio BC. Cross-cultural adaptation and validation of als Functional Rating Scale-Revised in Portuguese language. Arc Neuropsiquiatr. 2010;68(1):44-7.

10. Ferentinos P, Paparrigopoulos T, Rentzos M, Zouvelou V, Alexakis T, Evdokimidis I. Prevalence of major depression in ALS: comparison of a semi-structured interview and four self-report measures. Amyotroph Lateral Scler. 2011; 12(4):297-302.

11. Rabkin JG, Albert SM, Del Bene ML, O'Sullivan I, Tider T, Rowland LP, et al. Prevalence of depressive disorders and change over time in late-stage ALS. Neurology. 2005;65(1):62-7.

12. Rabkin JG, Wagner GJ, Del Bene M. Resilience and distress among amyotrophic lateral sclerosis patients and caregivers. Psychosom Med. 2000; 62:271-9. 